\title{
Population genetic structure and variability in Lindera glauca (Lauraceae) indicates low levels of genetic diversity and skewed sex ratios in natural populations in mainland China
}

\author{
Biao Xiong ${ }^{\text {Corresp., } 1}$, Limei Zhang ${ }^{2}$, Shubin Dong ${ }^{2}$, Zhixiang Zhang ${ }^{\text {Corresp. } 2}$ \\ ${ }^{1}$ College of Tea Science, Guizhou University, Guiyang, China \\ 2 Beijing Forestry University, Beijing, China \\ Corresponding Authors: Biao Xiong, Zhixiang Zhang \\ Email address: bxiong@gzu.edu.cn, zxzhang@bjfu.edu.cn
}

Lindera glauca (Lauraceae) is a tree of economic and ecological significance that reproduces sexually and asexually via apomictic seeds. It is widely distributed in the lowaltitude montane forests of East Asia. Despite the potential implications of a mixed reproductive system in terms of genetic diversity, few studies have focused on this aspect. In this study, the genetic structure of wild populations of L. glauca was investigated via genetic analyses. Overall, 13 nuclear microsatellites (nSSRs) and 5 chloroplast microsatellites (cpSSRs) were used to genotype 300 individual plants, taken from 20 wild populations and 2 cultivated populations ranging across nearly the entire natural distribution of mainland China. The populations exhibited low levels of genetic diversity (nSSR: $A_{R}=1.75, H o=0.32, H e=0.36 ;$ cpSSR: $N b=2.01, H r s=0.40$ ), and no significant effect of isolation by distance between populations existed, regardless of marker type (nSSR: $R^{2}=0.0401, P=0.068$; cpSSR: $R^{2}=0.033, P=0.091$ ). Haplotype networks showed complex relationships among populations, and the $\mathrm{H} 12$ haplotype was predominant in most populations. Analyses of molecular variance obtained with nuclear markers ( $F \mathrm{sc}=$ $\left.0.293, F_{\mathrm{ST}}=0.362\right)$ and chloroplast markers $\left(F \mathrm{SC}=0.299, F_{\mathrm{ST}}=0.312\right)$ were similar. The migration ratio of pollen flow versus seed flow in this study was negative $(r=-1.149)$. Results suggest that weak barriers of dispersal between populations and/or the similarity of founders shared between neighbors and distant populations, are indicative of the gene flow between populations more likely involving seeds. Wild L. glauca in mainland China was inferred to have highly skewed sex ratios with predominant females. In addition, some populations experienced a recent bottleneck effect, especially in Gujianshan, Chongqing, and southwest China (population GJS). It is suggested that few wild male individuals should be conserved in order to maintain overall genetic diversity in the wild populations of this species. These findings provide important information for the sustainable utilization and 
preservation of the overall genetic diversity of L. glauca. 
1 Population genetic structure and variability in Lindera glauca

2 (Lauraceae) indicates low levels of genetic diversity and skewed sex

3 ratios in natural populations in mainland China

4 Biao Xiong ${ }^{1,2^{*}}$, Limei Zhang ${ }^{2}$, Shubin Dong ${ }^{2}$, and Zhixiang Zhang ${ }^{2 *}$

$5{ }^{1}$ College of Tea Science, Guizhou University, Guiyang, China

$6 \quad{ }^{2}$ Beijing Forestry University, Beijing, China

7 Correspondence Author

8 Zhixiang Zhang, zxzhang@bjfu.edu.cn

9 No.35 Tsinghua East Road, Beijing 100083, China

10 Biao Xiong, bxiong@gzu.edu.cn

11 Jiaxiu South Road, Guiyang, Guizhou, 550025, China 


\section{Abstract}

Lindera glauca (Lauraceae) is a tree of economic and ecological significance that reproduces sexually and

asexually via apomictic seeds. It is widely distributed in the low-altitude montane forests of East Asia. Despite the

potential implications of a mixed reproductive system in terms of genetic diversity, few studies have focused on this

aspect. In this study, the genetic structure of wild populations of $L$. glauca was investigated via genetic analyses.

Overall, 13 nuclear microsatellites (nSSRs) and 5 chloroplast microsatellites (cpSSRs) were used to genotype 300

individual plants, taken from 20 wild populations and 2 cultivated populations ranging across nearly the entire

natural distribution of mainland China. The populations exhibited low levels of genetic diversity (nSSR: $A_{R}=1.75$,

$H o=0.32, H e=0.36$; cpSSR: $N b=2.01, H r s=0.40$ ), and no significant effect of isolation by distance between

populations existed, regardless of marker type (nSSR: $R^{2}=0.0401, P=0.068$; cpSSR: $R^{2}=0.033, P=0.091$ ).

Haplotype networks showed complex relationships among populations, and the H12 haplotype was predominant in

most populations. Analyses of molecular variance obtained with nuclear markers $\left(F \mathrm{sc}=0.293, F_{\mathrm{ST}}=0.362\right)$ and

chloroplast markers $\left(F_{\mathrm{sc}}=0.299, F_{\mathrm{ST}}=0.312\right)$ were similar. The migration ratio of pollen flow versus seed flow in

this study was negative ( $r=-1.149)$. Results suggest that weak barriers of dispersal between populations and/or the

similarity of founders shared between neighbors and distant populations, are indicative of the gene flow between

populations more likely involving seeds. Wild L. glauca in mainland China was inferred to have highly skewed sex

ratios with predominant females. In addition, some populations experienced a recent bottleneck effect, especially in

Gujianshan, Chongqing, and southwest China (population GJS). It is suggested that few wild male individuals

should be conserved in order to maintain overall genetic diversity in the wild populations of this species. These 
33 Keywords: Lindera glauca, genetic structure, apomixis, SSR marker, gene flow

\section{Introduction}

Plant populations respond to the changing environment and climate via phenotype shifts (Nicotra et al., 2010)

and, mainly through sexual reproduction, by bringing together high-fitness alleles that reside in different individuals

(Whitton et al., 2008). In general, sexual reproduction is predominant in eukaryotes and a nearly universal

characteristic of angiosperms. In some groups, however, some sexual plants can reproduce asexually via apomixis,

which is the production of clonal seeds in the absence of fertilization (Richards, 1986; Daniel et al., 2001),

producing exact genetic replicas of maternal plants (Daniel et al., 2001). Apomixis occurs in fewer than $1 \%$ of

flowering plant species, with an uneven distribution among lineages (Whitton et al., 2008). Apomixis occurs

sporadically among angiosperms (APG, 2003) (Whitton et al., 2008). In some genera (i.e., Taraxacum), apomictic

clones can be widely distributed and are temporarily ecologically successful (van Dijk, 2003; Majesky et al., 2012).

However, lack of diversity, the limited possibility of acquiring heritable variability (Richards, 1996), and an

increased mutation load leading to the extinction of clones (van Dijk, 2003), give apomicts an adaptive

disadvantage. In contrast, apomicts have lower reproductive costs over than sexuals, a high proportion of loci fixed

to heterozygous conditions, and significant advantages over sexuals in colonizing new areas (Majesky et al., 2012).

Due to these short-term advantages, natural populations of apomicts are of interest for agricultural development.

There are two major types of apomixis, adventitious embryony and gametophytic apomixis that differ in the

way embryos are formed (Whitton et al., 2008; Lo et al., 2009). The origin of the former is somatic tissue 
Poaceae, and Rosaceae. There are two ways for these to spread across space, direct dispersal via apomictic seeds, and indirect transmission via pollen (Whitton et al., 2008). For indirect transmission via pollen, the genes for maternal clonality can be transmitted via male gametes, and this mode of transmission may well be important in the establishment and spread of apomixis (Brock, 2004; Preite et al., 2015). Therefore, the transmission of apomixis genes to sexuals via pollen may be of long-term importance for the spread of apomixis, especially for an agriculturally important tree such as Lindera glauca. Lindera glauca (Sieb. et Zucc.) Blume (Lauraceae), a deciduous shrub or small tree with both apomixis (asexual reproduction by seeds) (Dupont, 2002) and a sexual reproduction system (Tsui et al., 1982; Tsui et al., 2008), is distributed extensively in low-altitude montane forests of central and southern mainland China, as well as in Japan, Korea, Vietnam and Taiwan (Wang, 1972; Chang, 1976; Zheng, 1983). As one of the main trees making up the shrubbery and young forest ecosystems in the central and southern areas of mainland China, this species has both economic value and ecological importance. Its fruits are rich in fatty acids and aromatic oils, and they contain terpenoids, flavonoids, and alkaloids, which are used for various applications in traditional medicine. Fruits are also used as raw materials to produce medicines, lubricants, and biochemical products (Zheng, 1983; Wang et al., 1994; Kim et al., 2014; Suh et al., 2015; Qi et al., 2016). Some root extract components, like N-methyllaurotetanine, exhibit significant anti-tumor metastatic activity (Kim et al., 2014; Suh et al., 2015) and some volatile oils from the leaves are used in the industrial production pf spices (Qi et al., 2016). Additionally, the L. glauca species has emerged as a novel potential source of biodiesel in China due to the high quality and quantity of its fruit oil (Lin et al., 2017; Xiong et al., 2018a). There has been increased scientific interest in the species, but relatively little remains known about its reproductive modes and their potential effects on genetic diversity in population dynamics and population differentiation. 
L. glauca is native to the mainland China, and diploids (2n=24) (Yang, 1999) with sexual reproduction and male plants have been known to exist in continental East Asia for several decades (Wang et al., 1972; Tsui et al., 1982; Tsui et al., 2008). In a study conducted in Japan, Dupont (2002) found that female L. glauca could asexually reproduce via seeds. Adult population sex ratios of other Lindera species observed in Japan ranged from equal to a strong male bias (including L. obtusiloba, L. umbellata, and L. erythrocarpa) (Dupont, 2002). However, recent empirical studies revealed how L. glauca males are very rare in mainland China, with females reproducing via apomixis. This indicates that natural populations have a mixed reproduction mode that includes apomixis and sexual propagation. Apomixis might play a major role in shaping the genetic structure of the species, by limiting gene flow within populations (Daniel et al., 2001). Interpopulation gene flow in plants is mediated by a combination of pollen and seed dispersal (Ennos, 1994). Some natural populations of apomicts retain residual sexual function as pollen donors and thus have the potential to spread apomixis via male gametes, thereby increasing the genetic diversity observed within apomictic populations (Whitton et al., 2008). In previous studies and records (Wang, 1972; Chang, 1976; Zheng, 1983; Dupont, 2002; Tsui et al., 2008), L. glauca is dioecious, and has bisexual or functionally unisexual flowers. However, our survey indicates that there was a very small amount of pollen from the staminode of female flowers (By 2, 3, 5-Triphenyltetrazolium chloride, or TTC method) (Hu, 1993), implying that they have the potential for natural pollination.

Thus, the genetic diversity and structure of natural populations of L. glauca may well be more complex than previously thought. It is essential to study the gene flow and estimate the relative rates of pollen and seed migration among natural populations. Furthermore, population bottleneck effect is thought to be responsible for the very low levels of genetic variation found in a number of species that now have large population sizes (Pannell, 2013). Given that there are very few males of L. glauca in mainland China over the last decade, and many males grown on Taiwan 
95

96

97

98

99

100

101

102

103

106

107

108

109

110

111

112

113

114

(Zhang, 2007), it is interesting to investigate whether natural populations in mainland China experienced a bottleneck effect or not?

In plants, organelle genomes are often uniparentally inherited (Wills et al., 2005). It is widely believed that plastid genomes are inherited through the maternal parent (Zhang and Sodmergen, 2010). Recently strict maternal inheritance of the plastid was observed in around $82 \%$ of the species in two large-scale studies totalling over 500 angiosperms (Corriveau and Coleman, 1988; Zhang et al. 2003; Zhang and Sodmergen, 2010). Strict paternal inheritance is rare, and population size matters as the levels of paternal transmission can be as low as $0.03 \%$ in determining the mode of inheritance of the chloroplast genome (Wang et al., 2004). Thus, considering the actual sample size per population, we assume that chloroplast DNA is maternal inheritance for L. glauca.

In the present study, the aims were to (1) investigate the genetic diversity of L. glauca populations in the mainland China, (2) detect genetic variation within and differentiation among natural populations, (3) assess the relative importance of pollen and seeds as agents of gene flow, and (4) determine whether natural populations experienced a decline in size (bottleneck effect). Molecular genetic analyses were performed and individuals in 20 wild populations (and 2 cultivated populations) of L. glauca were genotyped using 13 nuclear and 5 chloroplast microsatellite markers developed in the previous work (Xiong et al., 2016; Xiong et al., 2018b).

\section{Materials and Methods}

\section{Sample Collection}

During field expeditions carried out from 2013 to 2017, 300 individuals were sampled from 20 wild

populations and 2 cultivated populations, representing nearly the entire natural distribution of L. glauca in mainland 
115

116

117

118

119

120

121

122

123

124

125

126

127

128

129

130

131

132

133

134

135

stolons (Tsui et al., 1982), as found in our field survey. In order to avoid the collection of several ramets from the

same genet, a single sample was obtained from each cluster of shrubs in close proximity to a main tree, excluding

the surrounding young branches growing on the ground. Each sample (individual) in same population was collected

at least 10 meters apart. In some smaller populations, fewer than 10 plants of putatively nonclonal origin were

available. Overall sample sizes varied from 5 to 30 per wild population (Table 1). There was definite apomixis in

the individuals of two cultivated populations (based on our survey for three years), and we added it to global

analysis as a reference for wild populations. In the field, fresh leaves were immediately dried in silica gel after

collection, and preserved at room temperature until DNA extraction.

\section{DNA Extraction and Microsatellite Genotyping}

Genomic DNA was extracted from 100-150 mg of dried leaves per sample using a modified

cetyltrimethylammonium bromide (CTAB) method (Doyle et al., 1987). Microsatellite loci of all 300 individuals of

L. glauca were screened, including 13 polymorphic nuclear microsatellite markers (EST-based microsatellites;

hereafter nSSRs; Table S1) and 5 polymorphic chloroplast microsatellite markers (hereafter cpSSRs; Table S2). All

nSSRs and cpSSRs were labeled with fluorescently labeled nucleotides (forward primer with M13F) and detected by

capillary gel electrophoresis. Subsequent $\backslash$ steps and the PCR assay were conducted according to Xiong et al. (2016).

Genotyping was performed using an ABI 3730XL DNA Analyzer (Applied Biosystems, California, USA ) with a

GeneScan 500 LIZ Size Standard, and alleles for each locus were manually scored using GeneMarker version 2.2.0

software (SoftGenetics, State College, PA, USA).

\section{Data Analyses}

Raw data matrices containing information of alleles and haplotypes for $13 \mathrm{nSSR}$ and $5 \mathrm{cpSSR}$ loci were

checked for scoring errors. All SSR analyses were conducted with 300 samples. Data editing and formatting were

Peer] reviewing PDF | (2019:03:35773:7:0:NEW 4 Nov 2019) 
performed using GenAlEx v. 6.502 (Smouse et al., 2015).

The related indexes of genetic diversity were calculated as followed: for the nSSR data set, genetic diversity indices, including the number of alleles $\left(N_{A}\right)$, observed heterozygosity $(\mathrm{Ho})$, expected heterozygosity $(\mathrm{He})$, percentage of polymorphic loci (PPB), Wright's inbreeding coefficient $\left(F_{\text {IS }}\right)$, and Nei's (Nei, 1978) genetic distances, were estimated using GenAlEx v. 6.502 (Smouse et al., 2015) and POPGENE v. 1.32 (Yeh et al., 1999). The online package GENEPOP v. 4.1.4 (Rousset, 2008) was used to perform exact Hardy-Weinberg equilibrium $(H W E)$ tests and to test for the presence of private (null) alleles. The differentiation index $F_{\mathrm{ST}}$ was computed for pairs of populations using Arlequin v. 3.5.1.3 (Excoffier et al., 2005). Allelic richness $\left(A_{R}\right)$ was calculated using the software FSTAT v. 1.2 (Goudet, 1995). For the cpSSR data set, number of haplotypes ( $N b)$, genetic diversity $(D v)$, haplotype richness $(H r s)$, the number of private alleles (Prv), and the polymorphism information content (PIC) per locus were estimated using HAPLOTYPE v. 1.05 (Eliades and Eliades, 2009).

The population genetic structure was analyzed as followed: for the nSSR data set, the genetic structure of the 22 populations ( 20 wild and 2 cultivated) was analyzed using the Bayesian clustering approach implemented in STRUCTURE v. 2.3.4 (Pritchard et al., 2000), assuming an admixture model. In order to determine the most appropriate number of genetic clusters or groups (K value), $\mathrm{K}$ was set from 1 to 20 , and the analysis was run with 20 iterations for each $\mathrm{K}$ with a burn-in of 1,000,000 generations followed by 50,000 generations for the Markov chain Monte Carlo (MCMC) simulation. The admixture level for each individual (Q) was also inferred. The program STRUCTURE HARVESTER v. 0.6.94 (Earl and von Holdt, 2012) was used to estimate the number of population clusters based on the $\Delta \mathrm{K}$ parameter according to Evanno et al., (2005). Based on the most appropriate number of clusters suggested by Bayesian clustering, analysis of molecular variance (AMOVA) was performed using Arlequin, with 10,000 iterations for the permutation test. A neighbor-joining (NJ) tree was generated using POPTREE2 
157 (Takezaki et al.,2010) based on pairwise Nei (1978) genetic distances between populations determined by GenAlEx.

158 For the cpSSR data set, the Arlequin was used to determine pairwise $F_{\mathrm{ST}}$ values among all populations. A parsimony

159 network illustrating genetic relationships among haplotypes of $L$. glauca populations was generated using TCS v.1.1

160 (Clement et al., 2000).

161 Considering that isolation by distance (IBD) can be a key factor keeping populations apart by limiting gene

flow (Coyne and Orr, 2004), the IBD of wild L. glauca inter-population in mainland China was tested. In view of

the potential importance of pollen in the spread of apomixis (Mogie, 1992; Whitton et al., 2008), the pollen/seed

migration ratio $(r)$ was calculated. In order to examine IBD, the Mantel test was performed using GenAlEx,

correlating the pairwise genetic distances $\left[F_{\mathrm{ST}} /\left(1-F_{\mathrm{ST}}\right)\right]$ with the pairwise geographic distances (in kilometers). To

calculate $r$, we used the followed formula: $r=m p / m s=\left[\left(1 / F_{\mathrm{ST}}(\mathrm{n})-1\right)\left(1+F_{\mathrm{IS}}\right)-2\left(1 / F_{\mathrm{ST}}(\mathrm{cp})-1\right)\right] /\left(1 / F_{\mathrm{ST}}(\mathrm{cp})-1\right)$

(Ennos, 1994; Petit et al., 2005), where $m p$ is the pollen migration rate, $m s$ is the seed migration rate, $F_{\mathrm{ST}}$ values

(overall $F_{\mathrm{ST}}$ ) are population di $\square$ erentiation estimates derived from $\mathrm{AMOVA}, F_{\mathrm{ST}}(\mathrm{n})$ is the nuclear $F_{\mathrm{ST}}$ and $F_{\mathrm{ST}}(\mathrm{cp})$ is the chloroplast $F_{\mathrm{ST}}$.

Population bottlenecks were evaluated using BOTTLENECK v. 1.2.02 (Piry et al., 1990) with the infinite

alleles model (IAM) that a single mutation is allocated at a time and the resulting number of alleles is computed,

\section{Results}


177

178

179

180

181

182

183

\section{Genetic Variation}

A total of 74 alleles and 13 haplotypes were identified at 13 nSSRs and 5 cpSSRs across 300 individuals of $L$. glauca. For each locus, the number of alleles for 13 nSSR loci ranged from 3 (P-298) to 8 (XBLG-060), with a mean of 5.7 alleles (Table S1). In particular, $A_{R}$ ranged from 1.807 to 2.774 , with a mean of 2.329 , and PIC ranged from 0.363 to 0.711 , with a mean of 0.556 . Ho and $H e$ varied between 0.210 and 0.563 , with a mean of 0.380 , and between 0.380 and 0.754 , with a mean of 0.602 .

The total number of alleles of 20 wild populations across 13 nSSR loci varied from 22 (population SZY) to 44 (population ZJJ), with a mean of 32.9, and allelic richness ranged from 1.231 to 2.011 , with a mean of 1.740 (Table 2). Population $H o$ ranged from 0.108 to 0.708 and population $H e$ from 0.106 to 0.477 , with means of 0.328 and 0.376. The PPB ranged from $53.85 \%$ to $100 \%$, with a mean of $85 \%$ (Table 2). The values of total number of alleles, $H o, H e$, and PPB were all smaller in the two cultivation populations, with a mean of $18.5,0.212,0.145$, and $42.31 \%$, respectively. These parameter values of $\mathrm{Ho}(0.212), \mathrm{He}(0.145)$, and PPB (42.31\%) in two cultivated populations were much lower. Significant deviations from the $H W E$ indicating a heterozygote deficiency were detected in 9 of 22 populations. For some populations (KYS, WYS, ZJS, WJS, GJS, NHS, FHS, and ZJJ), negative $F_{\text {IS }}$ values within the populations were observed, indicating more heterozygotes than expected. However, none of the 13 nSSR loci with the heterozygote excesses appear when calculating it on all samples (Tables S1), and there is no evidence of private alleles within the data set. Among all wild samples (290), 277 individual plants had a unique multi-locus pattern after PCR amplification with 13 nSSRs primers, indicating that these samples were from different individuals. Of the remaining 13 individual plants, 5 pairs exhibited the same multi-locus pattern in pairs, and 3 individuals exhibited the same multi-locus pattern. Genetic diversity parameters for cpSSR loci are summarized in Table S2. All 5 cpSSR loci exhibited 2-3 
alleles per locus across all samples. $D v$ ranged from 0.115 to 0.249 per locus, and PIC varied from 0.155 to 0.218 .

Analyzing combinations of all alleles, there were 22 unique haplotypes (hereafter H; Fig. 1). All populations contained several haplotypes, except for populations ATM, YTH, NTB, FHS, TMS, and HZY (Fig. 1a). The network of plastid haplotypes was complex (Fig. 1b). Haplotype H12 exhibited the highest frequency and was detected in 18 of 20 wild populations (Table S3). Of the 22 haplotypes, 7 were private haplotypes excluding cultivated populations, Hrs per population ranged from 0 (populations ATM, NTB, YTH, TMS, and FHS) to 0.964 (population FJS), and the mean genetic distance between individuals $\left(\mathrm{D}^{2}{ }_{\text {sh }}\right)$ varied from 0 to 39.638 (population JGS) (Table 2).

\section{Genetic Clustering and Population Differentiation}

A Bayesian analysis based on $13 \mathrm{nSSRs}$ implemented in STRUCTURE showed the presence of 2 clusters $(\mathrm{K}=$ 2), with only slight admixture at the individual level in each population, except for population ATM (Fig. 2a). The $\Delta \mathrm{K}$ statistic developed by Evanno et al., indicated that the overall differences were not substantial (Fig. 2b). Cluster orange included 13 wild populations (ATM, JGS, LDZ, SJG, NTB, YTH, DBS, HMF, TMS, SQS, LYS, KYS, and WYS), and the remaining 7 wild populations and 2 cultivated populations were assigned to cluster blue. The NJ tree

(Fig. 3a) and principal coordinates analysis (Fig. 3b) based on the nSSR dataset supported the results of STRUCTURE analysis, indicating that 22 populations could be grouped into 2 clusters. However, the network diagram of all 22 unique plastid haplotypes revealed by 5 cpSSRs was complex (Fig. 1b), and failed to support the 2 distinct clusters revealed using nuclear data.

The 2 clusters revealed by STRUCTURE analysis were set as groups for AMOVA based on both the nSSR and cpSSR dataset (Table 3). Using the nSSR dataset, the majority of genetic variation was detected within populations 
218 (63.82\%), indicating a genetic differentiation mostly at the individual level. Nevertheless, a considerable proportion

219 of the total variation (26.42\%) was found among populations within groups, and a small amount of variation

$220(9.76 \%)$ occurred among the 2 groups. In contrast to the nSSR results, the AMOVA based on the cpSSR dataset

221 showed that a larger proportion of genetic variation could be attributed to variation within populations (68.84\%) and

222

223

among populations within groups $(29.37 \%)$, and little variation among groups $(1.79 \%)$. The overall $F_{\mathrm{ST}}$ values

calculated by AMOVA were $0.362(\mathrm{P} \leq 0.0001)$ for the $\mathrm{nSSR}$ dataset and $0.312(\mathrm{P} \leq 0.0001)$ for the cpSSR dataset.

\section{Isolation by Distance and Pollen/Seed Migration Ratios}

The estimates of genetic differentiation $\left(F_{\mathrm{ST}}\right.$ value) based on $13 \mathrm{nSSRs}$ ranged from 0.023 (between WJS and GJS) to 0.427 (between LDZ and FHS) (Table S4), excluding 2 cultivated populations. Only 4 pairwise comparisons (ATM and JGS, WJS and NHS, NTB and YTH, and WJS and GJS) showed significant $F$ st values $(\mathrm{P} \leq 0.05)$. Adopting a P-value of 0.01 , no significant correlation between pairwise genetic distance $\left[F_{\mathrm{ST}} /\left(1-F_{\mathrm{ST}}\right)\right]$ and geographic distance (in kilometers) was found using the Mantel test (Fig. 4) for the nSSR dataset $\left(R^{2}=0.0401, P=\right.$ $0.068)$ or the cpSSR dataset $\left(R^{2}=0.033, P=0.091\right)$, suggesting that $L$. glauca in mainland China does not exhibit significant IBD. The $F_{\mathrm{ST}}$ values for the nSSR and cpSSR were similar (Table 3), and the $r$ was -1.149 , indicating that most gene flow among populations occurs via seed, rather than via pollen.

\section{Population Bottleneck Effect}

Several populations had a significant excess of heterozygosity expected at mutation-drift equilibrium (i.e., He $>$ Heq) (Piry et al., 1990) under the 3 models in the bottleneck analysis, which indicated a deviation from mutation drift equilibrium in wild L. glauca populations (Table 4). More specifically, population GJS exhibited a significant bottleneck event according to the sign and Wilcoxon tests in all 3 models, indicating a population size

Peer) reviewing PDF | (2019:03:35773:7:0:NEW 4 Nov 2019) 
238

242

decline (bottleneck effect) in its history. Population WJS experienced a significant bottleneck event according to the sign test and Wilcoxon test for the IAM and TPM methods, and FHS exhibited a significant bottleneck event by

Wilcoxon test in all 3 models. SJG, FJS, and ZJS only exhibited a significant bottleneck event based on the sign and Wilcoxon tests for the IAM method (Table 4).

\section{Discussion}

\section{Genetic Variation within Populations}

In this study, sampling covered a large portion of the natural distribution, and overall genetic diversity across wild $L$. glauca populations exhibited low levels based on both nSSR (mean $A_{R}=1.74, H o=0.33, H e=0.38, F_{\text {IS }}=$ 0.14 ) and cpSSR (mean $\mathrm{Nb}=2.06, \mathrm{Hrs}=0.39$ ) loci. Our estimates of genetic diversity in L. glauca were almost half those of long-lived perennials $(H o=0.63, H e=0.68)$, out-crossing species $(H o=0.63, H e=0.65)$, and plants with wide distributions $(H o=0.57, H e=0.62)\left(\right.$ Nybom, 2004), which were lower than Laurus nobilis in Lauraceae $\left(A_{R}=\right.$ 3.22, $\mathrm{He}=0.56$ ) (Marzouki et al., 2009). There are several major factors influencing variation that can result, each by itself or in combination, in the low levels of genetic variation observed in wild L. glauca populations. Asexual reproduction through apomictic seeds can decrease genetic variation in a population especially in apomictic populations (Lo et al., 2009). Similarly, effective population size could seem like a limitation, due to the population being established from a limited number of individuals and a small sampling quantity. For two cultivated populations, these values were much lower than in wild populations, perhaps because apomixis reduces genetic diversity, or because of the potential confounding effect of small population sample size. Furthermore, the estimated values of genetic diversity therein are also lower than nSSR-based values found in literature $\left(A_{R}=2.61, \mathrm{He}=0.44\right.$, $F_{\text {IS }}=-0.37$ ) (Zhu et al., 2016).Differences in genetic variation between this study and the previous one are likely to 
258

be explained by the number of sampling populations and individuals the study of Zhu et al. (2016) included 6

populations, a total of 96 individual plants, while this study included 20 wild populations, making a total of 290 individual plants).

On the other hand, a marked similarity in the molecular variance revealed by the 2 types of markers (overall $F \mathrm{sc}=0.293$ and $F_{\mathrm{ST}}=0.362$ for nSSRs; 0.299 and 0.312 for $\mathrm{cpSSRs}$ ) was observed, indicating general consistency between chloroplasts and nuclear DNA. More specifically, predominant apomixis in wild L. glauca could explain how $F_{\mathrm{ST}}$ observed for nuclear markers is a little higher than that for chloroplast markers, and vice versa. In addition, apomictic reproduction of L. glauca could also affect the results. Therefore the use of clone-corrected data (removing the data of clones from the same parent) is necessary if clones are detected, because L. glauca trees could form clones via vegetative reproduction with stolons.

Nine populations had more heterozygotes than expected. STRUCTURE analysis showed that the 9 populations were grouped into one group and the rest into another, suggesting negative $F_{\text {IS }}$ is an important factor affecting group of population difference. Usually, positive $F_{\text {IS }}$ values within populations (JGS, LYS, and FJS) indicated inbreeding, and negative $F_{\text {IS }}$ of wild populations (KYS, WYS, ZJS, WJS, GJS, NHS, FHS, and ZJJ) suggested outbreeding. However, considering that clonality probably generates significant negative $F_{\text {IS }}$ in some wild plant populations with asexual reproduction when considering all individuals (Stoeckel et al., 2006), the observed negative $F_{\text {IS }}$ of wild populations (KYS, WYS, ZJS, WJS, GJS, NHS, FHS, and ZJJ), coupled with the result grouped by NJ tree and the cluster pattern of the NJ tree (blue cluster) (Fig. 3a), suggest that apomixis may have been common in these populations. On the other hand, global multilocus tests indicated that sexual reproduction did exist in these populations that were positive $F_{\text {IS }}$ values $\left(0<F_{\text {IS }}<1\right)$. There is mixed reproductive system existed in this species, thus explaining the $F_{\text {IS }}$ pattern. 
279 Genetic Differentiation among Populations

280

281

Populations can cluster according to habitat type or geographic distance. However, for species with predominantly asexual populations, like Daktulosphaira vitifoliae (Vorwerk and Forneck, 2006), Crataegus douglasii (Lo et al., 2009), and Taraxacum officinale (Majesky et al., 2012), no significant correlation exists between genetic distances and geographic distances. In this study, a correlation between genetic distances (as measured by $\left[F_{\mathrm{ST}} /\left(1-F_{\mathrm{ST}}\right)\right]$ values) and geographic distances (in kilometers) was not detected in L. glauca populations, regardless of marker type, suggesting that weak barriers to dispersal between populations and/or the common founders between neighbors, distant populations, and apomictic populations did not completely limit gene flow. Results indicate that sexual dispersion and apomixis co-occurred in the same natural population. However, further research is needed to investigate the extent to which apomixis limits gene flow, and the exact rate of sexual production and apomixis that occurred among and within populations.

According to Ennos' formula (1994), the migration ratio of pollen flow versus seed flow $(r)$ in this study was negative (-1.149), suggesting that gene flow between populations is more likely to involve seeds. Usually, the value of $r$ is positive in almost all angiosperm species (Ennos, 1994). The biased $r$ value could be explained by the reproductive mode in different populations being the apomictic seeds of females, coupled with the result that no staminate flower were found at field observation sites for 5 consecutive years. Considering that a situation where a few individuals can self-pollinate is likely, pollen from even just a few staminodes of female flowers may be associated with the negative $r$ value of pollen flow versus seed flow. However, because the formula is derived for a hermaphrodite species, it needs to be modified to account for the disproportionate maternal contribution from the females to the next generation if the exact $r$ value of $L$. glauca can be expected to be observed. 
299

300

301

302

\section{Source of Evolutionary Potential of Apomicts}

Although 22 haplotypes were observed across 20 wild populations and 2 cultivated populations of L. glauca, H12 accounted for $62.03 \%$ of overall haplotypes and was detected in all populations (Table S3), except for FHS, LYS, SZY, and HZY. This haplotype existing in many populations separated by considerable geographical distances

(e.g., greater than 1,720 km between KYS and GJS), coupled with the complex network (Fig. 1b), suggested three inferences to account for the observed result. First, these individuals from different populations had a relatively recent shared female founder. Second, there was an apomictic lineage for this species within some populations.

Third, the genome of this species has genetic traits that lead to apomixis, which might be induced by some factors

(e.g., biological stimulation, environmental influence, climate changing, etc.), and coexists with sexual reproduction in identical individual plants.

\section{The first inference could be explained by a hypothesis that the H12 haplotype may be associated with the}

migratory patterns of some birds responsible for the dispersion of apomictic seeds over a long distance. However, given that $\mathrm{H} 12$ is the most frequent and connected haplotype, probably is ancestral, this inference is not reliable.

Besides, despite conducting field observations for 5 consecutive years, few birds were found eating grown fruits of L. glauca, as well as few small mammals (e.g., Paguma larvata). The second inference means having an early maternal ancestor through apomictic reproduction for many individuals. However, all the living species are at the tips of the tree of life, and apomixis is a derived condition (APG, 2003, 2016; Horandl, 2006; Thompson and Whitton, 2006; Lo et al., 2009). Consequently, having ancestral asexual angiosperms is almost impossible, because asexuals fail to maintain sex and recombination in populations that are limited in size, therefore are unable to bring together high-fitness alleles that reside in different individuals. The third inference means that apomicts of L. glauca may be of very recent origin and have the ability to apomictically reproduce through mutations or losses of some 
320

321

322

323

324

sexual genes. A similar situation exists in some species, such as Taraxacum officinale that exhibit alternations of asexual and sexual histories of apomicts (Majesky et al., 2012), some hawthorns (Crataegus; Rosaceae) that have a population genetic structure of diploid sexual and polyploid apomicts (Lo et al., 2009), and a marbled crayfish (Procambarus virginalis) that reproduces through parthenogenesis (Gerhard et al., 2003; Ewen, 2018). Therefore, when coupled with the results of filed surveys that show apomixis occurred in all sampled populations, this haplotype (H12) is probably a predominant genotype existing in populations that have the ability to apomixis.

Above all, the authors reject the former two inferences that most populations across such long geographical distances have a relatively recent founder or an ancient apomictic ancestor, and believe the last inference that apomixis caused by mutations or losses of related genes makes this maternal haplotype (H12) present in many individuals from different populations more likely.

\section{Conjecture about Histories of Natural Populations}

According to the relationship $N e=4(N m N f) /(N m+N f)$, where $N m$ represents the number of males, and $N f$ represents the number of females (Beerli and Palczewski, 2010), the accurate values of $N e$ could not be calculated because there were no males in the samples collected. Even so, based on the rarity of male individuals in mainland

China, dioecious reproduction reported in the past several decades (Tsui et al., 1982; Wang, 1972), some specimens of branches of male individuals stored in the China National Herbarium (PE), and many males grown on Taiwan (Zhang, 2007), it is inferred that some natural populations of L. glauca recently experienced a severe bottleneck and male individuals experienced a decline, most likely resulting from anthropogenic causes. However, in order to test the above hypotheses and obtain more accurate results, further field investigations are necessary, including samples from male and female individuals in a population (especially males found on Taiwan), correcting for clone and 
340 apomictic reproduction, across the full range of $L$. glauca, including Japan, South Korea, and Taiwan.

\section{Implications for Conservation}

Genetic diversity is recognized as an important population attribute for both conservation and evolutionary

purposes (Cena et al., 2006). The purpose of the conservation of endangered and threatened species is to maintain

their contributions to overall genetic diversity. People usually focus only on endangered species and provide

lower level of genetic diversity in L. glauca than that of some other species in Lauraceae. The conclusion is that

wild L. glauca populations have female-skewed sex ratios, which was consistent with our field survey and sampling

for 5 consecutive years. The destruction of habitats in order to plant other commercial or medicinal crops and felling

by local farmers may explain the low frequency of male L. glauca in mainland China, although the species is

sexual reproduction in order to maintain this species' overall genetic diversity.

352

353

354

\section{Conclusion}

This study has shown low levels of genetic diversity in L. glauca across nearly its the entire natural distribution in mainland China. A complex correlation between populations was revealed by haplotype networks. Genetic structure within and among populations was similar at the nuclear and chloroplast levels. Furthermore, some populations experienced a recent bottleneck, and gene flow between populations is more likely to involve seed. This implies that wild L. glauca in mainland China has highly skewed sex ratios with predominant females. 


\section{Acknowledgements}

359

360

361

362

The authors thank Richard A. Ennos for his explanation of the formula of pollen/seed migration ratios. The authors thank reviewers Anonymous, Alejandra Lobo and Jean Beaulieu for their constructive suggestions about the original manuscript. The authors thank Rodrigo C. Gonçalves-Oliveira for his assistance with the AMOVA analysis, and Jigongshan National Nature Reserve for a part of the material collection.

\section{References}

APG (The Angiosperm Phylogeny Group). 2003. An update of the Angiosperm Phylogeny Group classification for the orders and families of flowering plants: APG II. Botanical Journal of the Linnean Society, 141:399-436. DOI 10.1111/j.10958339.2009.00996.x

APG (The Angiosperm Phylogeny Group). 2016. An update of the Angiosperm Phylogeny Group classification for the orders and families of flowering plants: APG IV. Botanical Journal of the Linnean Society, 181:1-20. DOI 10.1111/boj.12385

Beerli P, Palczewski M. 2010. Unified framework to evaluate panmixia and migration direction among multiple sampling locations. Genetics 185: 313-326. DOI 10.1534/genetics.109.112532

Beerli P., Felsenstein J. 1999. Maximum likelihood estimation of migration rates and population numbers of two populations using a coalescent approach. Genetics 152, 763-773. DOI 10.1017/S0016672399003766

Brock M. 2004. The potential for genetic assimilation of a native dandelion species, Taraxacum ceratophorum (Asteraceae), by the exotic congener T. officinale. American Journal of Botany, 91: 656-663. DOI 10.3732/ajb.91.5.656

Cena CJ, Morgan GE, Malette MD, Heath DD. 2006. Inbreeding, outbreeding and environmental effects on genetic diversity in 46 walleye (Sander vitreus) populations. Molecular Ecology 15: 303-320. DOI 10.1111/j.1365-294X.2005.02637.x

Chang CE. 1976. Volume 2: Lauraceae. In: Liu TS, eds. Flora of Taiwan. Taipei: Epoch press, 406-468 pp. 
378 Clement M, Posada D, Crandall KA. 2000. TCS: A computer program to estimate gene genealogies. Molecular Ecology 9: $1657-1659$.

Cornuet JM, Luikart G. 1996. Description and power analysis of two tests for detecting recent population bottlenecks from allele frequency data. Genetics 144: 2001-2014.

Corriveau JL, Coleman AW. 1988. Rapid screening method to detect potential biparental inheritance of plastid DNA and

Coyne JA, Orr HA. 2004. Speciation. Sinauer Associates, Sunderland, Mass.

Daniel G, Olivier L, Enrico P, Ueli G. 2001. Developmental genetics of gametophytic apomixis. Trends in Genetics 17: 597604. DOI 10.1016/S0168-9525(01)02454-4

Doyle JJ, Doyle JL. 1987. A rapid DNA isolation procedure for small quantities of fresh leaf tissue. Phytochemical Bulletin 19: 10.1038/hdy.1994.35

Earl DA, von Holdt BM. 2012. Structure Harvester: a website and program for visualizing structure output and implementing the evanno method. Conservation Genetics Resources 4: 359-361. DOI 10.1007/s12686-011-9548-7

Eliades NG, Eliades DG. 2009. HAPLOTYPE ANALYSIS: software for analysis of haplotype data. Distributed by the authors, Forest Genetics and Forest Tree Breeding, Georg-August University Goettingen, Germany.

Ennos RA. 1994. Estimating the relative rates of pollen and seed migration among plant populations. Heredity 72: 250-259. DOI

Evanno G, Regnaut S, Goudet J. 2005. Detecting the number of clusters of individuals using the software STRUCTURE: a 
Ewen C. 2018. Geneticists unravel secrets of super-invasive crayfish. Nature, 554: 157-158. DOI 10.1038/d41586-018-01624-y

Exco $\square$ er L, Laval G, Schneider S. 2005. Arlequin (version 3.0): an integrated software package for population genetics data analysis. Evolutionary Bioinformatics 1: 47-50.

Gerhard S, Anke B, Laura T, Reimann A, Mittmann B, Lukhaup C, Steuerwald F, Vogt G. 2003. Ecology:

Gonçalves-Oliveira RC, Wöhrmann T, Benko-Iseppon AM, Krapp F, Alves M, Wanderley MGL, Weising K. 2017.

Population genetic structure of the rock outcrop species Encholirium spectabile (Bromeliaceae): The role of pollination vs.

Goudet J. 1995. FSTAT (version 1.2): A computer program to calculate F-statistics. Journal of Heredity 86: 485-486. DOI seed dispersal and evolutionary implications. American Journal of Botany 104: 868. DOI 10.3732/ajb.1600410

Hu SY. 1993. Experimental methods in plant embryology ( I ) determination of pollen viability. Chinese Bulletin of Botany 10:

Kim KH, Moon E, Ha K, Suh WS, Kim HH, Kim SY, Choi SU, Lee KR. 2014. Bioactive lignan constituents from the twigs $60-62$. 10.1093/oxfordjournals.jhered.a111627

Horandl E. 2006. The complex causality of geographical parthenogenesis. New Phytologist 171:525-538. DOI 10.1111/j.14698137.2006.01769.x of Lindera glauca. Chemical \& Pharmaceutical Bulletin 62: 1136-1140. DOI 10.1248/cpb.c14-00381

Lin ZX, An JY, Wang J, Niu J, Ma C, Wang LB, Yuan GS, Shi LL, Liu LL, Zhang JS, Zhang ZX, and Lin SZ. 2017. Integrated analysis of 454 and Illumina transcriptomic sequencing characterizes carbon flux and energy source for fatty acid synthesis in developing Lindera glauca fruits for woody biodiesel. Biotechnology for Biofuels 10: 134. DOI 10.1186/s13068$017-0820-2$ 
Lo YYE, Stefanovic S, Dickinson TA. 2009. Population genetic structure of diploid sexual and polyploid apomictic hawthorns (Crataegus; Rosaceae) in the Pacific Northwest. Molecular Ecology 18: 1145-1160 DOI 10.1111/j.1365294X.2009.04091.x

Majesky L., Vasut RJ., Kitner M., Travnicek B. 2012. The pattern of genetic variability in apomictic clones of Taraxacum officinale indicates the alternation of asexual and sexual histories of apomicts. PLoS ONE 7: e41868. DOI 10.1371/journal.pone.0041868

Marzouki H, Nasri N, Jouaud B, Bonnet C, Khaldi A, Bouzid S, Fady B. 2009. Population genetic structure of Laurus nobilis L. inferred from transferred nuclear microsatellites. Silvae Genetica 58: 5-6.

Mogie M. 1992. The evolution of asexual reproduction. London: Chapman \&Hall, $276 \mathrm{pp}$.

Nei M. 1978. Estimation of average heterozygosity and genetic distance for small number of individuals. Genetics 89: 583-590.

Nicotra AB, Atkin OK, Bonser SP, Davidson AM, Finnegan EJ, Mathesius U., Poot P., Purugganan MD., Richards CL., Valladares F., van Kleunen M. 2010. Plant phenotypic plasticity in a changing climate. Trends in Plant Science 15: 684692. DOI 10.1016/j.tplants.2010.09.008

Nybom H. 2004. Comparison of di $\square$ erent nuclear DNA markers for estimating intraspecific genetic diversity in plants. Molecular Ecology 13: 1143-1155. DOI 10.1111/ j.1365-294X.2004.02141.x

Pannell JR. 2013. Bottleneck Effect. Brenner's Encyclopedia of Genetics 362-365. DOI 10.1016/b978-0-12-374984-0.00164-9

Petit RJ, Duminil J, Fineschi S, Hampe A, Salvini D, Vendramin GG. 2005. Invited review: comparative organization of chloroplast, mitochondrial and nuclear diversity in plant populations. Molecular Ecology 14: 689-701. DOI 10.1111/j.1365294X.2004.02410.x

Piry S, Luikart G, Cornuet JM. 1990. BOTTLENECK: a computer program for detecting recent reductions in the e $\square$ ective size using allele frequency data. Journal of Heredity 90: 502-503. DOI 10.1093/jhered/90.4.502 
441

442

Preite V., Snoek LB., Oplaat C., Biere A., van der Putten WH., Verhoeven KJ. 2015. The epigenetic footprint of poleward range-expanding plants in apomictic dandelions. Molecular Ecology 24: 4406-4418. DOI 10.1111/mec.13329

Pritchard JK, Stephens M, Donnelly P. 2000. Inference of population structure using multilocus genotype data. Genetics 155: $945-959$.

Qi J, Xiong B, Zhang ZX, Zhen AG, Pu FG. 2016. Diversity analysis on fatty acid composition of Lindera glauca fruit from different provenances. Journal of the Chinese Cereals and Oils Association 31: 72-78. ([In Chinese])

Richards AJ. 1986. Plant breeding systems. London: Unwin Hyman, 529 pp.

Richards AJ. 1996. Genetic variability in obligate apomicts of the genus Taraxacum. Folia Geobot Phytotax 31: $405-414$.

Rousset F. 2008. GENEPOP'007: a complete re-implementation of the GENEPOP software for Windows and Linux. Molecular Ecology Resources 8: 103-106. DOI 10.1111/j.1471-8286.2007.01931.x

Smouse PE, Whitehead MR, Peakall R. 2015. An informational diversity framework, illustrated with sexually deceptive orchids in early stages of speciation. Molecular Ecology Resources 15: 1375-1384. DOI 10.1111/1755-0998.12422.

Stoeckel S, Grange J, Fernandez-Manharres F, Bilger I, Frascaria-Lacoste N, Mariette S. 2006. Heterozygote excess in a self-incompatible and partially clonal forest tree species_Prunus avium L. Molecular Ecology 15: 2109-2118. DOI 10.1111/j.1365-294X.2006.02926.x

Suh WS, Kim KH, Kim HK, Choi SU, Lee KR. 2015. Three new lignan derivatives from Lindera glauca (Siebold et Zucc.) Blume. Helvetica Chimica Acta 98: 1087-1094. DOI 10.1002/hlca.201500002

Takezaki N, Nei M, Tamura K. 2010. POPTREE2: software for constructing population trees from allele frequency data and computing other population statistics with Windows-interface. Molecular Biology and Evolution 27: 747-752.

Thompson SL, Ritland K. 2006. A novel mating system analysis for modes of self-oriented mating applied to diploid and polyploid arctic Easter daisies (Townsendia hookeri). Heredity 97:119-126. DOI 10.1038/sj.hdy.6800844 
462

464

465

466

467

468

469

470

471

472

473

Tsui HP, Werff H. 2008. Volume 7: Lauraceae and Hernandiaceae. In: Li HW, eds. Flora of China. Beijing \&St. Louis: Science Press \& Missouri Botanical Garden Press, 146-147 pp.

Tsui HP, Xia ZD, Li JL. 1982. Volume 31: Lauraceae and Hernandiaceae. In: Li HW, eds. Flora of China Vol. Beijing: Science Press, 393-394 pp.

van Dijk PJ. 2003. Ecological and evolutionary opportunities of apomixis: insights from Taraxacum and Chondrilla. Philosophical Transactions of the Royal Society Biological Sciences 358: 1113-1121.

Vorwerk S, Forneck F. 2006. Reproductive mode of grape phylloxera (Daktulosphaira vitifoliae, Homoptera: Phylloxeridae) in Europe: molecular evidence for predominantly asexual populations and a lack of gene flow between them. Genome 49:678687. DOI $10.1139 / \mathrm{g} 06-028$

Wang T, Li Y, Shi Y, Reboud X, Darmency H, Gressel J. 2004. Low frequency transmission of a plastid-encoded trait in Setaria italica. Theoretical and Applied Genetics 108:315-320. DOI 10.1007/s00122-003-1424-8

Wang WC. 1972. Higher plants iconography of China. Beijing: Science Press, 853 pp.

Wang Y, Gao X, Yu X, Cheng S, Kong L. 1994. Study on the resource and its utilizations of Lindera glauca in China. Henan Science 12: 331-334. ([In Chinese])

Whitton J., Sears CJ., Baack EJ., Otto SP. 2008. The dynamic nature of apomixis in the angioperms. International Journal of Plant Sciences, 169: 169-182. DOI 10.1086/523369

Wills DM, Hester ML, Liu A, Burke JM. 2005. Chloroplast SSR polymorphisms in the Compositae and the mode of organellar inheritance in Helianthus annuus. Theoretical and Applied Genetics 110: 941-947. DOI 10.1007/s00122-004-1914-3

Xiong B, Dong SB, Qi J, Zhang LM, Ha DL, Ju YX, Zhang ZX. 2016. Development and characterization of microsatellite loci for Lindera glauca (Lauraceae). Applications in Plant Science 4: 1600088. DOI 10.3732/apps.1600088

Xiong B, Dong SB, Zhang ZX. 2018a. Biodiesel from Lindera glauca oil, a potential non-food feedstock in Southern China. 
Xiong B, Zhang LM, Xie L, Dong SB, Zhang ZX. 2018b. Complete chloroplast genome of a valuable economic tree, Lindera glauca (Lauraceae) and comparison with its congeners. Pakistan Journal of Botany 50: 2189-2196.

Yeh FC, Yang RC, Boyle T. 1999. POPGENE Version 1.31. Microsoft window-based freeware for population genetic analysis. University of Alberta and Centre for International Forestry Research.

Zhang Q, Liu Y, Sodmergen. 2003. Examination of the cytoplasmic DNA in male reproductive cells to determine the potential

Zhang YM. 2007. The search for the observation of Lindera glauca, Lauraceae in Dadu mountain. Taiwan Academy of Ecology,

Zheng WQ. 1983. Dendrology of China. Beijing: Chinese Forestry Publishing House Press, 701-702 pp.

Zhu SS, Ding YQ, Yap ZY, Qiu YX. 2016. De novo assembly and characterization of the floral transcriptome of an population genetics. Molecular Biology Reports 43: 1243-1250. 
498 Fig. 1. (A) Chloroplast haplotypes and sampling location present in Lindera glauca populations analyzed in the 499 present study (see Table 1 for details). Each population is represented by a triangle, and pie charts are shown 500 when a population was present in more than one haplotype. The green background shows the provincial-level 501 distribution of the species in China. (B) Haplotype network was generated by program TCS. Each haplotype is 502 represented by a single color, and circle sizes correspond to the relative frequency of a particular haplotype in 503 the total sample.

Fig. 2. (A) Bayesian inference using STRUCTURE $(\mathrm{K}=2)$ based on $13 \mathrm{nSSR}$ markers from 22 populations of L. galuca, (B) $\mathrm{K}=2$ appeared to be the optimal number of clusters by showing the $\Delta \mathrm{K}$ at its peak.

507

Fig. 3. (A) Neighbor-joining (NJ) dendrogram based on Nei's (1978) genetic distances among populations. (B) nSSR markers.

512 Fig. 4. (A) Figure plot of geographical distance against genetic distance for 22 populations of L. glauca based on 13 nSSR markers (B) and 5 cpSSR markers. 


\section{Table $\mathbf{1}$ (on next page)}

Table 1 Plant material of Lindera glauca analyzed in the current study. Sample locations and abbreviations of 20 wild and two cultivated population s used in the main text are listed below. 
1 Table 1 Plant material of Lindera glauca analyzed in the current study. Sample locations and abbreviations of

220 wild and two cultivated populations used in the main text are listed below.

\begin{tabular}{|c|c|c|c|c|c|c|}
\hline $\begin{array}{l}\text { Population } \\
\text { Code }\end{array}$ & Number & $\begin{array}{c}\text { Samples } \\
\text { accession } \\
\text { no. }\end{array}$ & $\begin{array}{l}\text { Longitude } \\
\qquad\left(\mathrm{E}^{\circ}\right)\end{array}$ & $\begin{array}{l}\text { Latitude } \\
\qquad\left(\mathrm{N}^{\circ}\right)\end{array}$ & $\begin{array}{l}\text { Elevation } \\
\text { (m) }\end{array}$ & Location \\
\hline ATM & 10 & A14-10 & 115.8602778 & 31.2243972 & $646-834$ & Tianma, Jinzhai, Anhui \\
\hline JGS & 30 & J13-09 & 114.0883389 & 31.8658833 & $203-317$ & Jigongshan, Xinyang, Henan \\
\hline LDZ & 20 & L14-04 & 114.2575139 & 31.9452917 & $154-261$ & Dongzhai, Luoshan, Henan \\
\hline SJG & 15 & S14-10 & 115.5421083 & 31.7488389 & $243-476$ & Jingangtai, Shangcheng, Henan \\
\hline NTB & 10 & N14-04 & 113.4231917 & 32.3289139 & $241-256$ & Tongbaishan, Nanyang, Henan \\
\hline YTH & 10 & Y14-04 & 115.8647444 & 31.0572889 & $647-734$ & Taohuachong, Yingshan, Hubei \\
\hline DBS & 10 & D14-09 & 115.8391528 & 31.0087028 & $834-1003$ & Dabieshan, Yingshan, Hubei \\
\hline HMF & 10 & H14-09 & 113.0076417 & 28.4467750 & $224-257$ & Heimifeng, Wangcheng, Hunan \\
\hline TMS & 10 & T14-09 & 119.4495389 & 30.3255389 & $359-432$ & Tianmushan, Lin'an, Zhejiang \\
\hline SQS & 5 & S15-08 & 118.0738639 & 28.9580278 & $567-572$ & Sanqingshan, Yushan, Jiangxi \\
\hline LYS & 5 & LY15-07 & 118.2822889 & 32.2834417 & $134-138$ & Langyashan, chuzhou, Anhui \\
\hline KYS & 5 & K15-09 & 121.7357528 & 37.2661972 & $136-141$ & Kunyushan, Muping, Shandong \\
\hline FJS & 8 & F15-05 & 108.7698111 & 27.8495556 & $586-597$ & Fanjingshan, Tongren, Guizhou \\
\hline WYS & 7 & W16-04 & 117.9581530 & 27.6423810 & $206-217$ & Wuyishan, Wuyishan, Fujian \\
\hline ZJS & 30 & Z17-04 & 118.8264001 & 32.0671503 & $238-256$ & Zijinshan, Nanjing, Jiangsu \\
\hline WJS & 15 & WJ17-04 & 107.4861333 & 31.2340670 & $763-791$ & Wangjiangshan, Dazhou, Sichuan \\
\hline GJS & 22 & G17-04 & 106.6017170 & 28.9666002 & $1104-1186$ & Gujianshan, Qijiang, Chongqing \\
\hline NHS & 30 & HS17-05 & 112.7194830 & 27.2638000 & $233-255$ & Nanyuehengshan, Hengyang, Hunan \\
\hline FHS & 8 & FH17-04 & 108.4688137 & 32.8432889 & $813-897$ & Fenghuangshan, Hanyin, Shanxi \\
\hline ZJJ & 30 & ZJ17-05 & 110.5002670 & 29.1373330 & $291-368$ & Huilongshan, Zhangjiajie, Hunan \\
\hline $\mathrm{SZY}^{*}$ & 5 & SZ16-10 & 121.1781194 & 31.0778861 & 45 & Shanghai Botanical Garden, Shanghai \\
\hline $\mathrm{HZY}^{*}$ & 5 & HZ15-09 & 113.3594389 & 23.1793639 & 11 & $\begin{array}{l}\text { South China Botanical Garden, } \\
\text { Guangzhou, Guangdong }\end{array}$ \\
\hline
\end{tabular}

3 Note: * cultivated population. SZY cultivars were introduced from Jiangsu between 1973-1977. HZY cultivars were introduced from Guangdong in before

4 1985; All Samples accession numbers refer to voucher specimens deposited in the Beijing Forestry University (BJFU); Geographic coordinates and

5 elevation were obtained with portable GPS receiver.

6 
Table 2 (on next page)

Table 2 Genetic diversity within populations of $L$. glauca revealed by 13 nSSR and 5 cPSSR markers. 
1 Table 2 Genetic diversity within populations of $L$. glauca revealed by $13 \mathrm{nSSR}$ and $5 \mathrm{cpSSR}$ markers.

\begin{tabular}{|c|c|c|c|c|c|c|c|c|c|c|c|}
\hline \multirow{2}{*}{ Population } & \multicolumn{6}{|c|}{ nSSRs } & \multicolumn{5}{|c|}{ cpSSRs } \\
\hline & $N_{A \mathrm{nSSR}}$ & $A_{R}$ & Ho & $\mathrm{He}$ & $F_{\text {IS }}$ & PPB(\%) & $N_{\text {AcpSSR }}$ & $\mathrm{Nb}$ & $\operatorname{Prv}$ & $H r s$ & $\mathrm{D}^{2} \mathrm{sh}$ \\
\hline ATM (10) & 31 & 1.823 & 0.262 & 0.400 & $0.3917 *$ & 84.62 & 1 & 1.000 & 0 & 0.000 & 0.000 \\
\hline JGS (30) & 40 & 1.837 & 0.390 & 0.400 & 0.043 & 100 & 8 & 4.018 & 1 & 0.777 & 39.638 \\
\hline LDZ (20) & 34 & 1.689 & 0.192 & 0.344 & $0.4608^{*}$ & 92.31 & 4 & 1.527 & 0 & 0.363 & 1.091 \\
\hline SJG (15) & 38 & 2.011 & 0.241 & 0.471 & $0.5139 *$ & 92.31 & 2 & 1.142 & 0 & 0.133 & 0.427 \\
\hline NTB (10) & 35 & 1.916 & 0.162 & 0.431 & $0.6561 *$ & 92.31 & 1 & 1.000 & 0 & 0.000 & 0.000 \\
\hline YTH (10) & 41 & 1.992 & 0.239 & 0.456 & $0.5169^{*}$ & 84.62 & 1 & 1.000 & 0 & 0.000 & 0.000 \\
\hline DBS (10) & 29 & 1.588 & 0.108 & 0.288 & $0.6571^{*}$ & 84.62 & 2 & 1.220 & 0 & 0.200 & 4.000 \\
\hline HMF (10) & 30 & 1.636 & 0.115 & 0.313 & $0.6617^{*}$ & 92.31 & 4 & 2.381 & 1 & 0.644 & 13.227 \\
\hline TMS (10) & 38 & 1.987 & 0.239 & 0.447 & $0.5071^{*}$ & 100 & 1 & 1.000 & 0 & 0.000 & 0.000 \\
\hline SQS (5) & 26 & 1.711 & 0.231 & 0.317 & $0.3717^{*}$ & 69.23 & 3 & 2.273 & 0 & 0.700 & 3.200 \\
\hline LYS (5) & 29 & 1.747 & 0.277 & 0.319 & 0.238 & 61.54 & 3 & 2.778 & 0 & 0.800 & 16.480 \\
\hline KYS (5) & 30 & 1.734 & 0.415 & 0.319 & -0.200 & 76.92 & 2 & 1.471 & 0 & 0.400 & 0.320 \\
\hline FJS (8) & 28 & 1.771 & 0.327 & 0.380 & 0.205 & 92.31 & 7 & 6.400 & 1 & 0.964 & 24.343 \\
\hline WYS (7) & 22 & 1.231 & 0.264 & 0.188 & -0.333 & 53.85 & 2 & 1.324 & 1 & 0.286 & 8.229 \\
\hline ZJS (30) & 37 & 1.431 & 0.708 & 0.477 & -0.470 & 100 & 4 & 1.230 & 1 & 0.193 & 3.915 \\
\hline WJS (15) & 31 & 1.392 & 0.518 & 0.396 & -0.275 & 76.92 & 3 & 1.923 & 0 & 0.514 & 2.011 \\
\hline GJS (22) & 28 & 1.929 & 0.479 & 0.382 & -0.233 & 76.92 & 3 & 2.142 & 0 & 0.558 & 22.940 \\
\hline NHS (30) & 40 & 1.823 & 0.469 & 0.404 & -0.145 & 100 & 5 & 1.531 & 0 & 0.359 & 2.231 \\
\hline FHS (8) & 26 & 1.748 & 0.462 & 0.338 & -0.307 & 69.23 & 1 & 1.000 & 0 & 0.000 & 0.000 \\
\hline ZJJ (30) & 44 & 1.806 & 0.472 & 0.453 & -0.025 & 100 & 9 & 4.787 & 1 & 0.818 & 7.342 \\
\hline Mean & 32.9 & 1.740 & 0.328 & 0.376 & -0.137 & 85 & 3.3 & 2.057 & 0.3 & 0.386 & 7.470 \\
\hline $\mathrm{SZY}^{\mathrm{a}}(5)$ & 16 & 1.692 & 0.192 & 0.108 & -0.667 & 23.07 & 2 & 2.000 & 1 & 1.000 & 0.800 \\
\hline $\mathrm{HZY}^{\mathrm{a}}(\mathbf{5})$ & 21 & 1.921 & 0.231 & 0.182 & -0.059 & 61.54 & 1 & 1.000 & 0 & 0.000 & 0.000 \\
\hline Mean & 18.5 & 1.807 & 0.212 & 0.145 & -0.363 & 42.31 & 1.5 & 0.500 & 0.5 & 0.500 & 0.400 \\
\hline
\end{tabular}

2 Notes: ${ }^{a}$ cultivated population; $N_{\text {anSSR }}=$ number of alleles across 13 nuclear SSR loci; $A_{R}=$ allelic richness; $H o=$ observed heterozygosity; $H e=$

3 expected heterozygosity; $F_{\mathrm{IS}}=$ inbreeding coefficient; $\mathrm{PPB}=$ percentage of polymorphic loci; $N_{\text {acpSSR }}=$ number of alleles across five chloroplast

4 SSR loci; $N b=$ number of haplotypes; Hrs = haplotype richness; $P r v=$ private haplotypes; $\mathrm{D}^{2} \mathrm{sh}=$ the mean genetic distance between individuals;

5 * significant deviations from $H W E$ determined by a global multilocus test implemented in GENEPOP $(\mathrm{P}<0.005)$. 


\section{Table 3(on next page)}

Analysis of molecular variance (AMOVA) and degrees of freedom (df) based on 13 nuclear SSR and five chloroplast SSR markers for populations of $\mathrm{L}$. glauca. The groups revealed by a Bayesian STRUCTURE analysis $(K=2)$ were considered for both marker types. 
1 Table 3 Analysis of molecular variance (AMOVA) and degrees of freedom (df) based on 13 nuclear SSR and 2 five chloroplast SSR markers for populations of $L$. glauca. The groups revealed by a Bayesian STRUCTURE 3 analysis were set as 2 for AMOVA.

\begin{tabular}{|c|c|c|c|c|c|c|}
\hline \multirow[t]{2}{*}{ Source of variation } & \multicolumn{3}{|c|}{ nSSRs } & \multicolumn{3}{|c|}{ cpSSRs } \\
\hline & df & $\%$ of Variation & $F$-statistics & df & $\%$ of Variation & $F$-statistics \\
\hline Among groups & 1 & 9.76 & $F_{\mathrm{CT}}=0.09756^{*}$ & 1 & 1.79 & $F_{\mathrm{CT}}=0.01793$ \\
\hline Among populations within groups & 20 & 26.42 & $F_{\mathrm{SC}}=0.29281 *$ & 20 & 29.37 & $F_{\mathrm{SC}}=0.29903 *$ \\
\hline Within populations & 273 & 63.82 & $F_{\mathrm{ST}}=0.36180 *$ & 273 & 68.84 & $F_{\mathrm{ST}}=0.31160 *$ \\
\hline
\end{tabular}

4 Notes: $F_{C T}=$ differentiation among groups; $F_{S C}=$ differentiation among populations within groups; $F_{S T}=$ differentiation among populations; $*$ significant 5 values with $\mathrm{P} \leq 0.0001$. 


\section{Table 4(on next page)}

Table 4 Bottleneck analyses for 20 wild populations of $L$. glauca. 
1 Table 4 Bottleneck analyses for 20 wild populations of $L$. glauca

\begin{tabular}{|c|c|c|c|c|c|c|}
\hline \multirow[t]{2}{*}{ Population } & \multicolumn{2}{|r|}{ IAM } & \multicolumn{2}{|r|}{ TPM } & \multicolumn{2}{|r|}{ SMM } \\
\hline & Sign test & Wilcoxon test & Sign test & Wilcoxon test & Sign test & Wilcoxon test \\
\hline ATM & $0.0366^{*}$ & 0.0674 & 0.0596 & 0.1230 & 0.2577 & 0.2061 \\
\hline JGS & 0.3046 & 0.2439 & 0.3968 & 1.0000 & 0.4540 & 0.7354 \\
\hline LDZ & 0.3681 & 0.3804 & 0.5193 & 0.9097 & 0.4268 & 0.4697 \\
\hline SJG & $0.0047 * *$ & $0.0105^{*}$ & $0.0469^{*}$ & 0.0522 & 0.1750 & 0.1514 \\
\hline NTB & 0.2277 & 0.0923 & 0.2999 & 0.1514 & 0.3827 & 0.6772 \\
\hline YTH & 0.0782 & 0.2402 & 0.3010 & 0.8984 & 0.2911 & 0.4131 \\
\hline DBS & 0.5698 & 0.9658 & 0.4498 & 0.7002 & 0.3485 & 0.3652 \\
\hline HMF & 0.3258 & 0.9697 & 0.4538 & 0.9097 & 0.4342 & 0.5693 \\
\hline TMS & 0.3221 & 0.2734 & 0.5841 & 0.5879 & 0.0534 & 0.8394 \\
\hline SQS & 0.1909 & $0.0371^{*}$ & 0.3072 & 0.3594 & 0.2811 & 0.7344 \\
\hline LYS & 0.5500 & 0.4609 & 0.3552 & 0.8438 & 0.2784 & 0.4609 \\
\hline KYS & 0.6099 & 0.8457 & 0.1162 & 0.4316 & 0.1274 & 0.1934 \\
\hline FJS & $0.0234^{*}$ & $0.0134^{*}$ & 0.1536 & 0.0923 & 0.4000 & 0.2661 \\
\hline WYS & 0.4625 & 0.9375 & 0.3955 & 0.9375 & 0.3416 & 0.5781 \\
\hline ZJS & $0.0117^{*}$ & $0.0067 * *$ & $0.0247^{*}$ & 0.0803 & 0.1177 & 0.2439 \\
\hline WJS & $0.0105^{*}$ & $0.0049 * *$ & $0.0208^{*}$ & $0.0137^{*}$ & 0.1171 & 0.1309 \\
\hline GJS & $0.0066^{* *}$ & $0.002 * *$ & $0.0106^{*}$ & $0.0098^{* *}$ & $0.0189^{*}$ & $0.0098^{*}$ \\
\hline NHS & 0.1557 & 0.6355 & 0.2295 & 1.0000 & 0.5266 & 0.7869 \\
\hline FHS & 0.1297 & $0.0098 * *$ & 0.1693 & $0.0098^{* *}$ & 0.1244 & $0.0371 *$ \\
\hline ZJJ & 0.3329 & 0.1909 & 0.3724 & 0.5417 & 0.3253 & 0.5417 \\
\hline
\end{tabular}

2 Notes: * significant values with $\mathrm{P} \leq 0.05$, ** significant values with $\mathrm{P} \leq 0.01$.

3 


\section{Figure 1}

Figure 1

Fig. 1. (A) Chloroplast haplotypes and sampling location present in Lindera glauca populations analyzed in the present study (see Table 1 for details). Each population is represented by a triangle, and pie charts are shown when a population was present in more than one haplotype. The green background shows the provincial-level distribution of the species in China. (B) Haplotype network was generated by program TCS. Each haplotype is represented by a single color, and circle sizes correspond to the relative frequency of a particular haplotype in the total sample. 

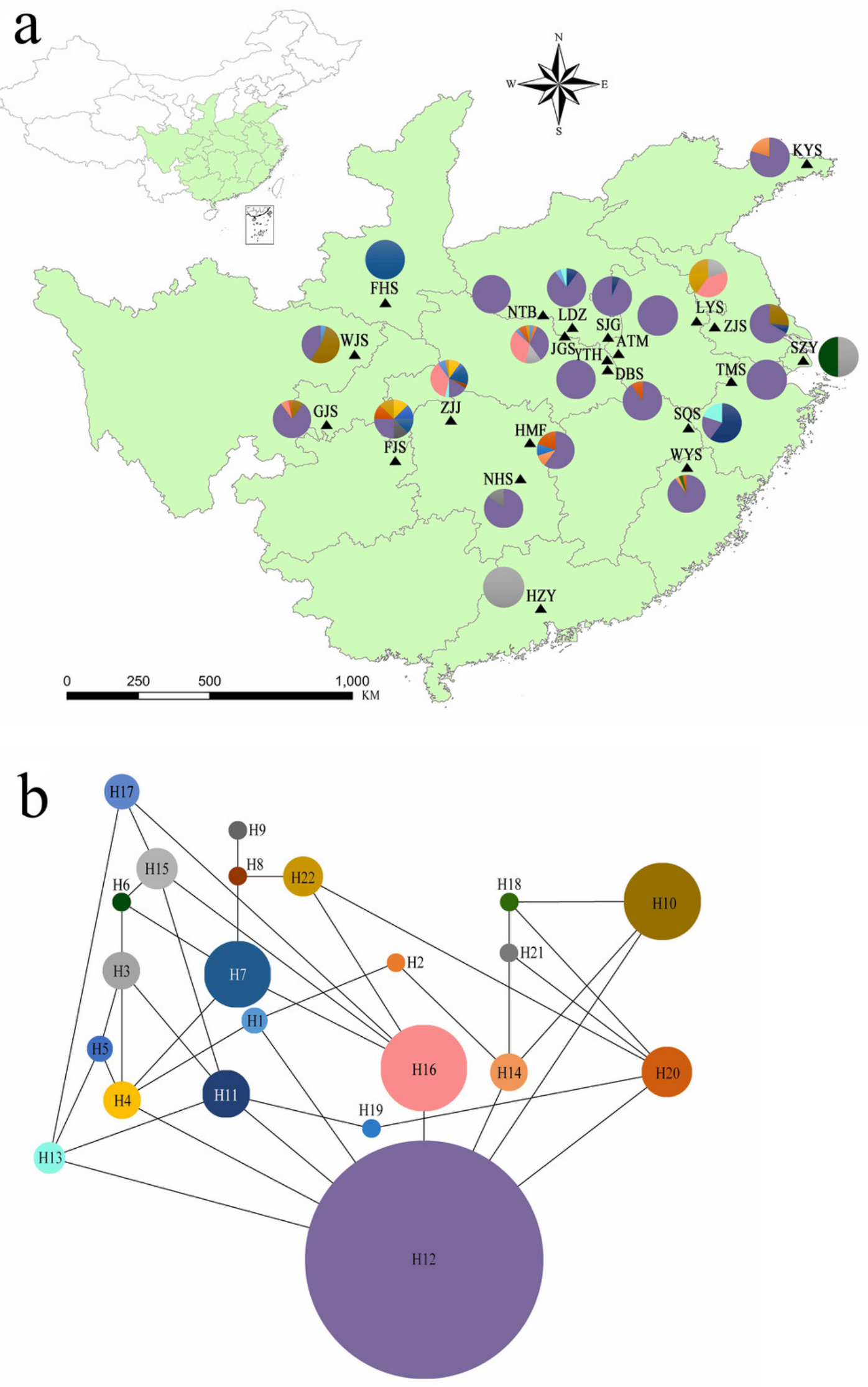


\section{Figure 2}

Figure $2(A)$ Bayesian inference using STRUCTURE $(K=2)$ based on 13 nSSR markers from 22 populations of $L$. galuca, (B) $K=2$ appeared to be the optimal number of clusters by showing the $\Delta K$ at its peak.

$\mathrm{a}$

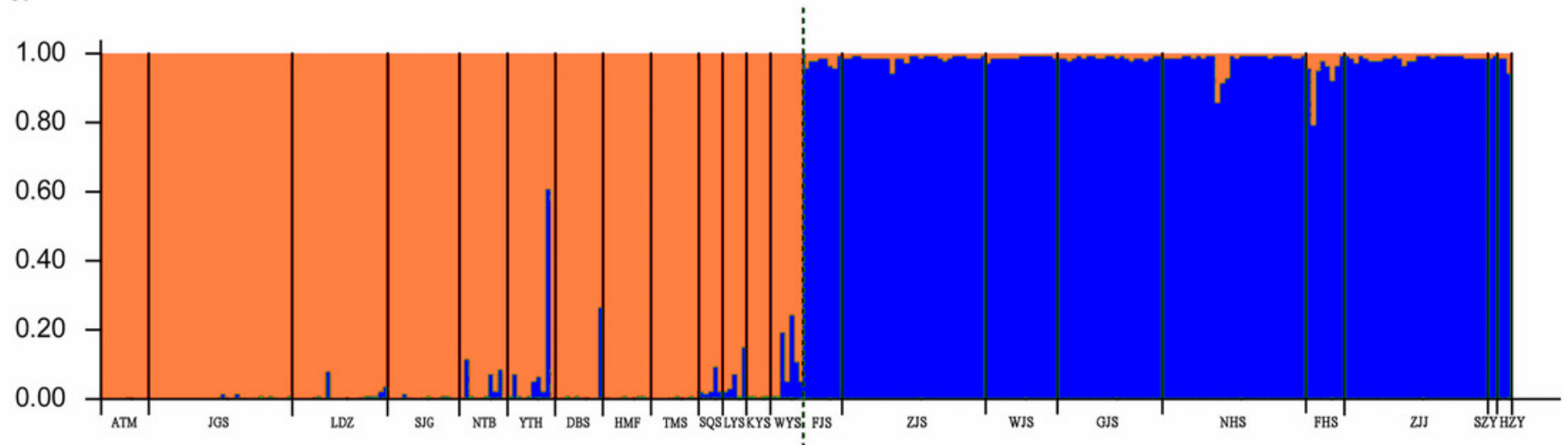

b

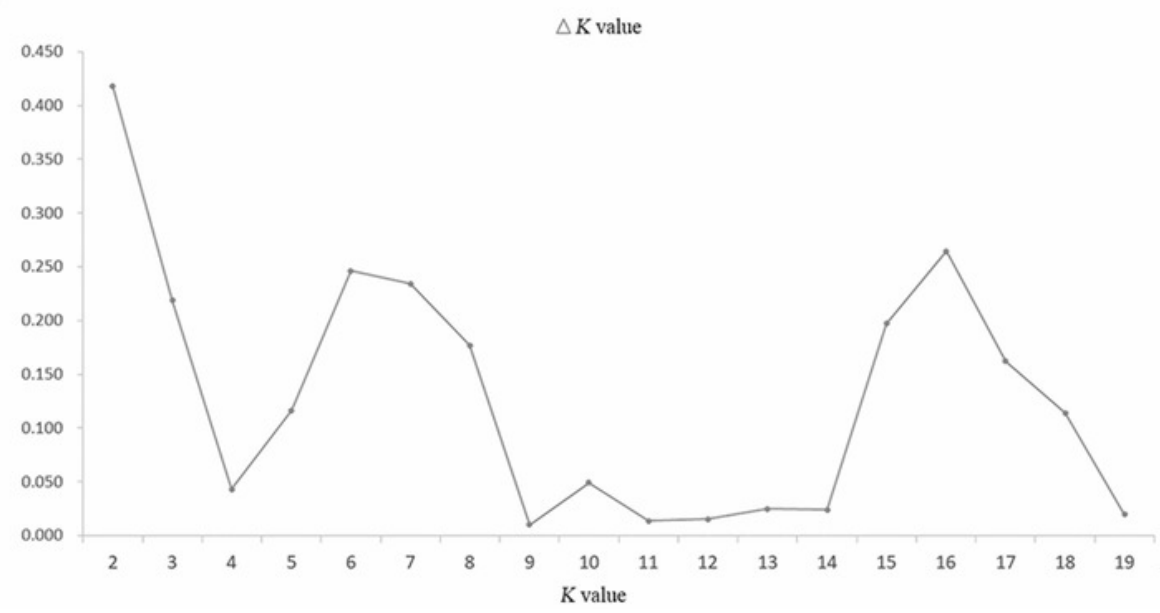


Figure 3

Figure 3 (A) Neighbor-joining (NJ) dendrogram based on Nei's (1978) genetic distances among populations. (B) Principal coordinates analysis ( $\mathrm{PCOA}$ ) of genetic variation across 22 populations of $L$. glauca based on 13 nSSR markers. 


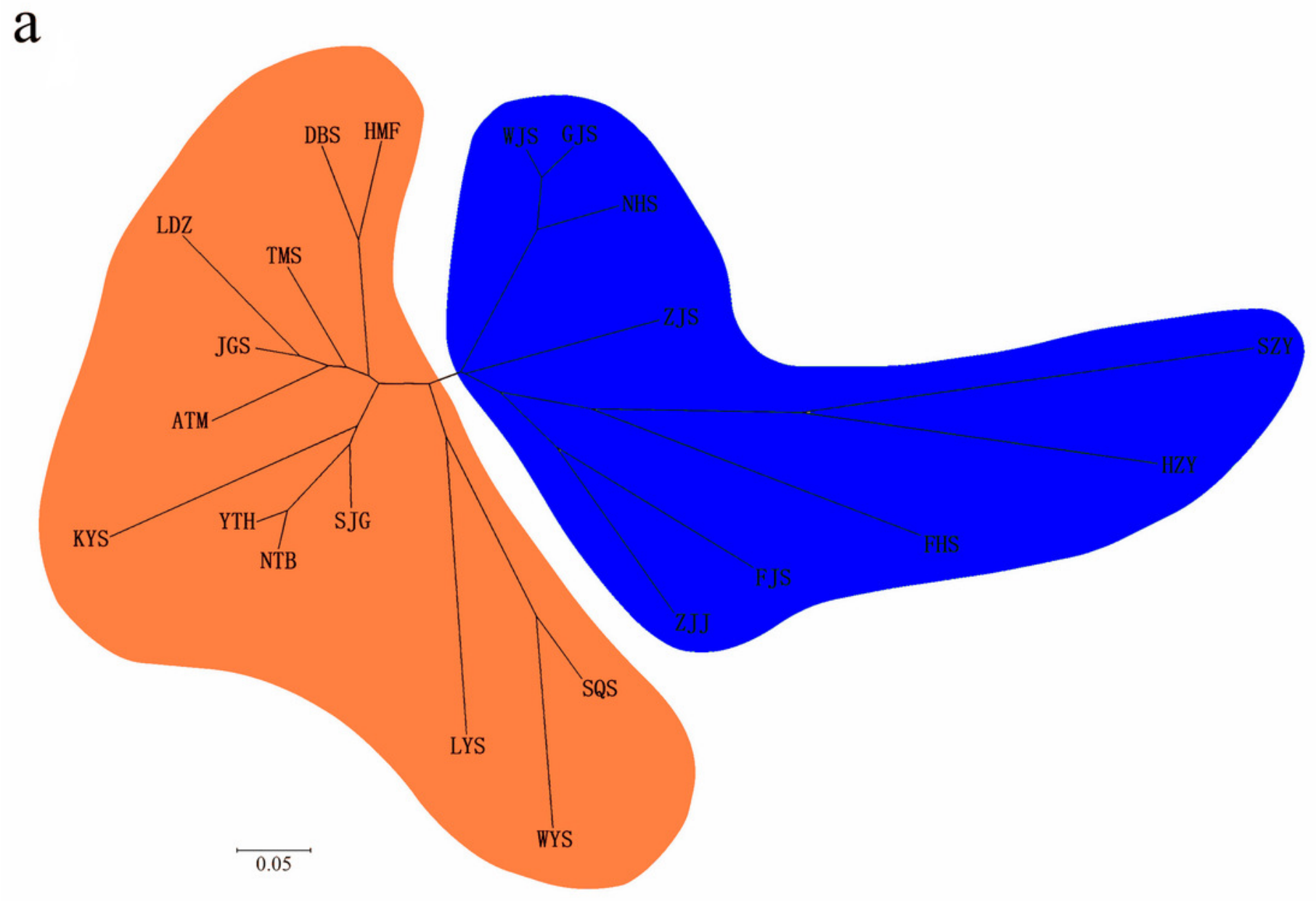

b

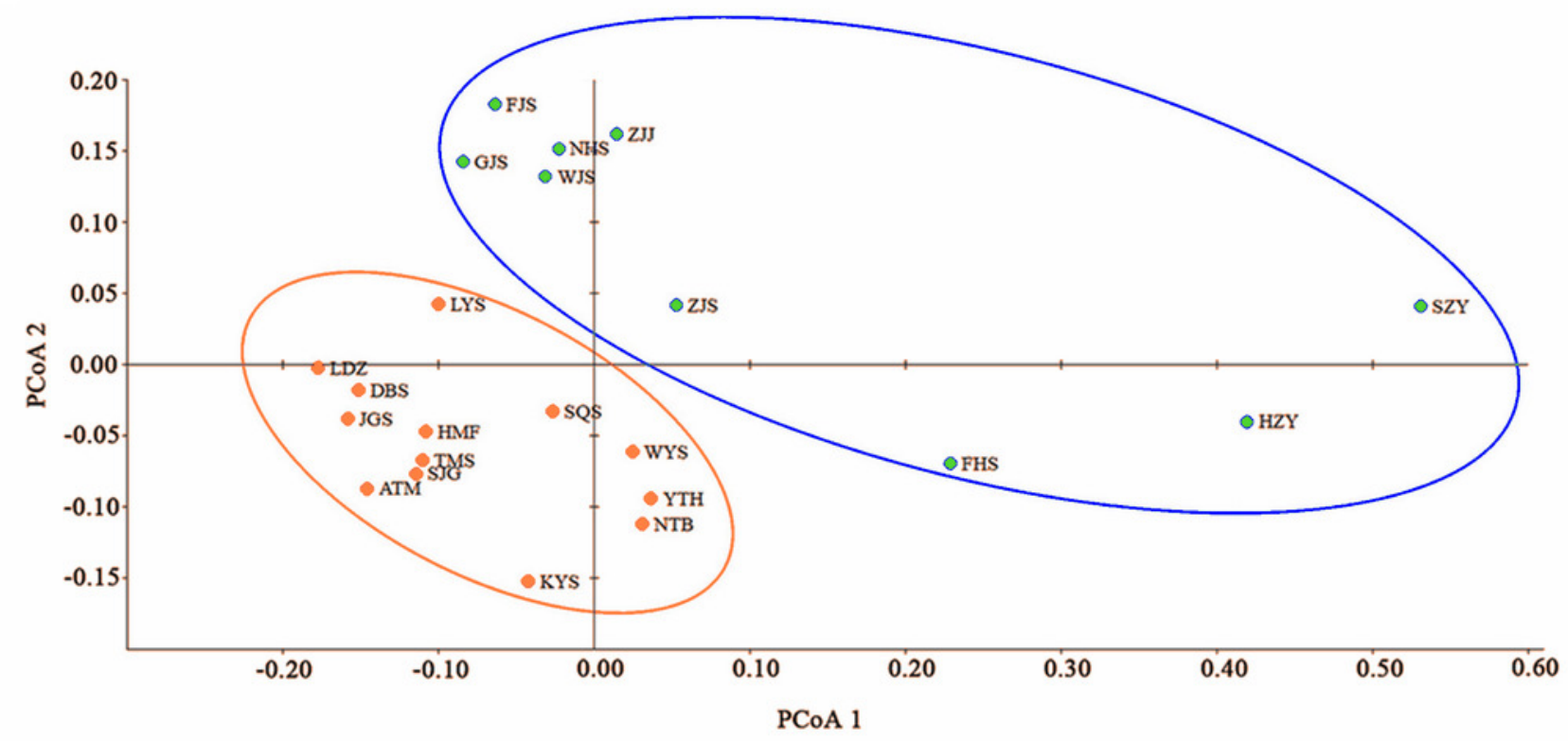


Figure 4

Figure 4 (A) Figure plot of geographical distance against genetic distance for 22 populations of $L$. glauca based on 13 nSSR markers (B) and 5 cPSSR markers.
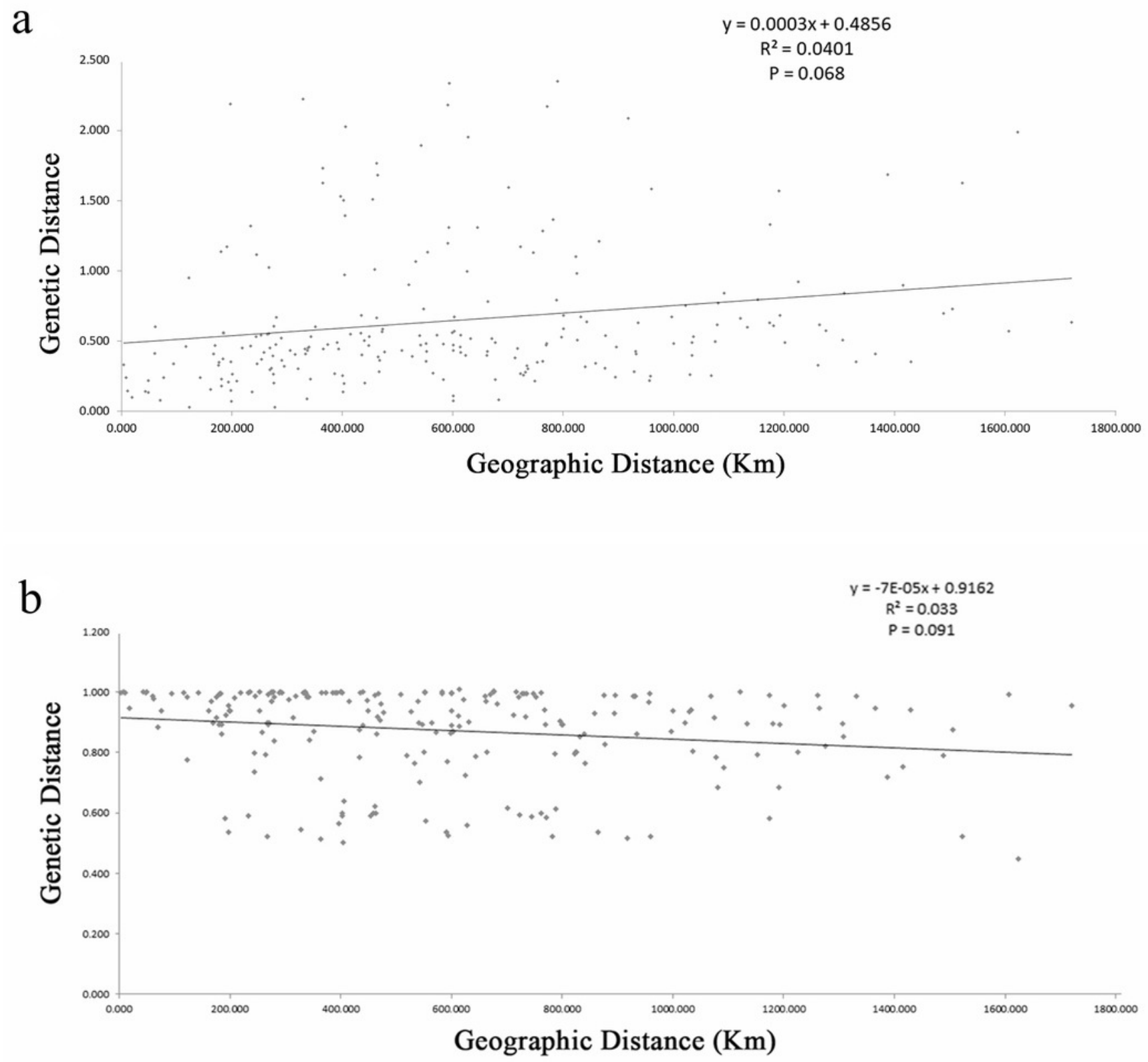